\title{
Causes and Consequences of Metabolic Acidosis in Patients after Kidney Transplantation
}

\author{
Alexander Ritter ${ }^{a} \quad$ Nilufar Mohebbi ${ }^{a, b}$ \\ aDivision of Nephrology, University Hospital of Zurich, Zurich, Switzerland; \\ bPraxis und Dialysezentrum Zürich-City, Zurich, Switzerland
}

\section{Keywords}

Bone metabolism · Bicarbonate $\cdot$ Renal tubular acidosis $\cdot$ Graft failure $\cdot$ Mortality

\begin{abstract}
Background: Metabolic acidosis (MA) is a common complication in kidney transplantation $(\mathrm{KTX})$. It is more prevalent in $\mathrm{KTx}$ than in $\mathrm{CKD}$, and it occurs at higher glomerular filtration rates. The pathophysiologic understanding of MA in KTx and its clinical impact has been highlighted by few recent studies. However, no guidelines exist yet for the treatment of MA after KTx. Summary: MA in KTx seems to share pathophysiologic mechanisms with CKD, such as impaired ammoniagenesis. Additional kidney transplant-specific factors seem to alter not only the prevalence but also the phenotype of MA, which typically shows features of renal tubular acidosis. There is evidence that calcineurin inhibitors, immunological factors, process of donation, donor characteristics, and diet may contribute to MA occurrence. According to several mainly observational studies, MA seems to play a role in disturbed bone metabolism, cardiovascular morbidity, declining graft function, and mortality. A better understanding of the pathophysiology and evidence from randomized controlled trials, in particular, are needed to clarify the role of MA and the potential benefit of alkali treatment in KTx. Alkali therapy might not only be beneficial but also cost effective and safe. Key Messages: MA seems to be associated with several negative outcomes in KTx. A deeper understanding of the pathophysiology and clinical consequences of MA in KTx is crucial. Clinical trials will have to determine the potential benefits of alkali therapy.

(C) 2020 The Author(s)

Published by S. Karger AG, Basel
\end{abstract}




\section{Introduction}

Acid-base homeostasis is crucial for human life. It is maintained mainly by adaptation of respiration and the kidneys. Metabolic acidosis (MA) is an acid-base disorder defined by an increased hydrogen ion concentration in the serum, resulting in low blood $\mathrm{pH}$ paralleled by decreased serum bicarbonate.

MA is a well-recognized complication of CKD and defined by a serum bicarbonate concentration $<22 \mathrm{mmol} / \mathrm{L}$ according to the KDIGO guidelines [1]. By increasing acid excretion and ammoniagenesis, the kidneys counteract a decrease in serum bicarbonate concentration. However, as the glomerular filtration rate (GFR) declines, the prevalence of MA increases [2, $3]$. A recent meta-analysis of numerous CKD, general population, and high cardiovascular risk cohorts demonstrated a substantial number of patients presenting with MA. The prevalence of MA averaged from 12.2 to $17.9 \%$ in nondiabetic CKD stage G3 patients and from 26.9 to $36.6 \%$ in CKD stage G4 patients according to the KDIGO classification [3].

Importantly, also in kidney transplant recipients (KTRs), high prevalences of MA ranging from 12 to 58\% - have been reported. However, compared to CKD cohorts with similar degrees of renal function impairment, MA appears to be consistently more prevalent and occurs at higher GFR levels after kidney transplantation (KTx) [4]. The underlying mechanisms are not fully elucidated yet but potentially attributed to additional transplant-specific factors.

Chronic MA in CKD is associated with increased mortality and morbidity, such as reduced mineral bone content, growth retardation in children, increased protein catabolism, muscle wasting, chronic inflammation, impaired insulin sensitivity and cardiac function [5-8]. Moreover, there is increasing evidence that chronic MA can lead to progression of CKD [914]. In addition, alkalinizing therapies in CKD patients reduced the decline of GFR in several randomized controlled trials (RCTs) [15-21]. Consequently, the KDIGO guidelines suggest bicarbonate substitution in CKD patients if serum bicarbonate concentration is $<22 \mathrm{mmol} / \mathrm{L}$ [1]. In contrast to CKD patients, only few retrospective studies have been published on the impact of MA on graft function and mortality in KTRs [22-26]. Thus, although the first description of MA after KTx was more than half a century ago, there is still a lack of guidelines on how to deal with chronic MA in KTRs [27]. This review aims to give an overview on the current knowledge about the pathophysiology and the evidence from clinical studies on chronic MA in KTRs.

\section{Causes of MA after KTx}

The kidneys play a key role in the regulation of the acid-base balance by reabsorption of filtered bicarbonate, regeneration of bicarbonate via ammoniagenesis, and acid excretion [28]. While some of the pathogenic mechanisms of chronic MA in KTRs are similar to those in CKD patients, others seem to be specific to KTx.

Mechanisms in CKD

The daily load of nonvolatile acids can be eliminated by the kidneys via ammoniagenesis in the proximal tubular cells and secretion of mainly ammonium by type A intercalated cells in the collecting duct. Progression of CKD is characterized by interstitial fibrosis and tubular atrophy. This loss of renal mass leads to an increased ammoniagenesis in the remaining nephrons to ensure adequate renal acid secretion [29-31]. Impaired ammoniagenesis and reduced excretion of nonvolatile acids into the urine have been shown to be the main mechanisms of MA contributing to CKD progression [5, 32, 33]. Accordingly, key molecules required 
for renal ammoniagenesis and ammonia excretion were found to be highly downregulated in a CKD rat model [34]. Interestingly, a recent analysis of patients of the NephroTest cohort with CKD stages G1-4 showed that renal acid excretion may already be diminished without a simultaneous reduction of venous total carbon dioxide $\left(\mathrm{tCO}_{2}\right)$ and significantly correlates with estimated glomerular filtration rate (eGFR) decline [35]. Thus, it is possible that other parameters than serum bicarbonate concentration such as urinary ammonium excretion might serve as early markers of MA in CKD.

Furthermore, early animal studies demonstrated that the compensatory increase of ammoniagenesis in surviving nephrons leading to ammonium-dependent complement activation causes tubulointerstitial injury $[30,36]$. In the last years, data from animal experiments and clinical studies showed a pathogenic impact of endothelin, aldosterone, and angiotensin-II in the context of MA, contributing to tubulointerstitial injury and CKD progression $[16,17,19,37-39]$. In line with these studies, an upregulation of genes of proinflammatory cytokines was reported from a gene expression analysis of Madin-Darby canine kidney cells exposed to acid stress, supporting the hypothesis that inflammation induced by acidosis could lead to renal fibrosis and decline of kidney function [40]. Taken together, impaired ammoniagenesis, ammonium-dependent complement activation, and ammonium-independent factors such as endothelin, aldosterone, and angiotensin-II seem to be involved in the progression of CKD by MA.

\section{Additional Features and Mechanisms Specific to KTx}

As mentioned above, chronic MA already appears at higher eGFR levels in KTx patients than in the CKD population. This circumstance suggests that there are additional mechanisms, which are specific for the transplant setting. In KTRs, the typical features of renal tubular acidosis (RTA) such as normal anion gap normo- or hyperchloremic MA are usually found, while in CKD-associated MA, reduced serum chloride levels and a normal or increased anion gap are common [4, 41]. Although the first case report of chronic MA in KTx published in 1967 showed impaired renal acid excretion with the features of a mixed proximal and distal RTA [27], distal RTA type I (classic RTA) and distal RTA type IV (hyperkalemic RTA) are the common types seen in the course of KTx [41]. However, proximal RTA type II - due to tubular injury and hyperparathyroidism - has also been reported early after transplantation $[42,43]$. As the tubular damage and hyperparathyroidism resolve, RTA may diminish entirely within the first 6 months post transplantation [44-46].

\section{Calcineurin Inhibitors}

Calcineurin inhibitors (CNIs) seem to play an essential role in the prevalence of MA in KTRs. Since the 1980s, CNIs are a key component of long-term immunosuppressive regimen after organ transplantation. Several studies could demonstrate an association of CNIs with the occurrence of chronic MA, with some evidence that it occurs more frequently with tacrolimus than cyclosporine $A[22,24,41,47,48]$. This effect seems to be dose dependent $[49,50]$. Human and animal studies have shown that both cyclosporine A and tacrolimus may cause functional tubular damage $[47,51,52]$. The different molecular mechanisms that lead to an alteration of the tubular electrolyte transport causing RTA were characterized in animal experiments. Cyclosporine A seems to block the adaptation of type B intercalated cells in the distal tubule by inhibiting the peptidyl-prolyl cis-trans isomerase activity [51]. With intake of tacrolimus, the expression or cellular distribution of important acid-base transport proteins such as the vacuolar proton pump, the anion exchanger AE1, or the sodium bicarbonate carbonate cotransporter NBCe1 was altered [52]. In addition, the use of mycophenolate formulations, antibiotics, and other drugs may cause chronic diarrhea in some patients after transplantation and subsequently contribute to nonanion gap MA. 


\section{Immunological Factors}

RTA occurs in autoimmune diseases such as systemic lupus erythematosus or Sjogren's syndrome. The immunological mechanisms of autoantibodies cross-reacting with intercalated cells and impairing their function have been reported in Sjogren's syndrome [53]. Thus, immunological factors like rejections might also be associated with MA; however, there is no definitive proof yet and results are conflicting. Earlier studies suggested that hyperchloremic acidosis was an early sign of allograft rejection [54, 55]. Another publication reported on a KTR suffering from acute rejection accompanied by severe MA, which entirely resolved after rejection treatment. Histologic findings revealed a reduced immunoactivity of the vacuolar proton pump and AE 1 in intercalated cells of the collecting duct, postulating an immunological pathogenesis of the MA [56]. However, in a small biopsy study, lower expression of the vacuolar proton pump after transplantation was found independent of acute rejection episodes [57]. In addition, in larger studies, no associations of acute rejections and MA were detected $[22,24,41,58]$.

\section{Donation and Donor}

Donation and donor-associated factors may play a role in the development of chronic MA - in particular since the incidence of MA early after transplantation is highest - but there is a paucity of evidence so far [4]. Five studies found a higher percentage or an association of MA in KTRs after deceased donor KTx [4, 22-24, 58], while in three other studies, no association was found for donor type [41, 49, 58, 59]. Only one study reported on prolonged cold ischemia time and an association with MA 3 months after transplantation [24]. So far, no association with donor age [22, 24] or sex was identified [22]. To our knowledge, no results on the influence of donor kidney function on MA occurrence after transplantation have been published yet.

\section{Dietary Factors}

High dietary acid intake in combination with reduced acid excretion capacity of the graft could result in a higher prevalence of MA after KTx. A study comprising 707 KTRs analyzed the impact of diet on acid-base homeostasis. Dietary acid load was identified as a relevant component contributing to MA in KTRs, leading to an increased net acid excretion (NAE). High dietary acid intake in the form of animal protein as well as a low consumption of fruit and vegetables was associated with significant lower blood $\mathrm{pH}$ and serum bicarbonate levels. NAE was calculated from 24-h urine collections to assess the metabolic acid load [60]. Additionally, dietary acid load could also uncover an underlying incomplete RTA, a common subclinical tubular defect in KTRs.

Other Factors

The single kidney state with a higher blood flow and changes in chemical and electrical transtubular gradients might contribute to a reduced renal NAE not only in nephrectomized patients but also in KTRs [61].

\section{Consequences of MA after KTx}

The majority of the evidence about consequences of MA derives from experimental and clinical studies in the non-transplant CKD setting. However, we feel that there is a great need for more data and firm evidence in the transplant population, especially to give physicians guidance for treatment of this metabolic disorder. Table 1 gives an overview of existing clinical studies about MA in KTx. 
Table 1. Overview of clinical studies on MA after KTx

\begin{tabular}{|c|c|c|c|c|c|c|}
\hline Reference & Study design & $N^{*}$ & $\begin{array}{l}\text { Study duration/ } \\
\text { follow-up }\end{array}$ & Intervention & Outcome/endpoint & $\begin{array}{l}\text { Result: } \\
\text { impact of } \\
\text { acidosis }\end{array}$ \\
\hline \multicolumn{7}{|l|}{ Bone metabolism } \\
\hline Heaf et al. [62] & $\begin{array}{l}\text { Cross-sectional } \\
\text { analysis }\end{array}$ & 125 & na & na & BMD & Yes \\
\hline $\begin{array}{l}\text { Yakupoglu et al. } \\
\text { [48] }\end{array}$ & $\begin{array}{l}\text { Cross-sectional } \\
\text { analysis }\end{array}$ & 823 & na & na & Serological biomarkers & Yes \\
\hline Brazier et al. [24] & $\begin{array}{l}\text { Cross-sectional } \\
\text { analysis }\end{array}$ & 914 & na & na & $\begin{array}{l}\text { Serological biomarkers, } \\
\text { graft failure, death, and } \\
\text { composite outcome }\end{array}$ & $\begin{array}{l}\text { Yes (MA } \\
\text { with } \\
\text { acidemia) }\end{array}$ \\
\hline Starke et al. [63] & RCT & 30 & 1 year & $\begin{array}{l}\text { Potassium citrate } \\
\text { or potassium } \\
\text { chloride }\end{array}$ & $\begin{array}{l}\text { Bone biopsy, } \\
\text { serological biomarkers, } \\
\text { and BMD }\end{array}$ & $\begin{array}{l}\text { Yes (none } \\
\text { for BMD) }\end{array}$ \\
\hline Keven et al. [58] & $\begin{array}{l}\text { Cross-sectional } \\
\text { analysis }\end{array}$ & 68 & na & na & BMD & None \\
\hline Franke et al. [64] & $\begin{array}{l}\text { Prospective } \\
\text { observational cohort } \\
\text { study }\end{array}$ & 389 & $\begin{array}{l}\text { Median follow-up } \\
3.4 \text { years }\end{array}$ & na & Growth & Yes \\
\hline Schulte et al. [26] & $\begin{array}{l}\text { Retrospective } \\
\text { observational cohort } \\
\text { study }\end{array}$ & 4,741 & $\begin{array}{l}\text { Median follow-up not } \\
\text { reported; endpoints } \\
\text { reported at } 5 \text { years } \\
\text { after KTx }\end{array}$ & na & $\begin{array}{l}\text { DCGF, mortality, and } \\
\text { bone fractures }\end{array}$ & None \\
\hline \multicolumn{7}{|c|}{ Cardiovascular events } \\
\hline Djamali et al. [23] & $\begin{array}{l}\text { Retrospective } \\
\text { observational cohort } \\
\text { study }\end{array}$ & 2,128 & $\begin{array}{l}\text { Median follow-up } \\
4.0 \text { years }\end{array}$ & na & $\begin{array}{l}\text { CVEs and all-cause } \\
\text { mortality }\end{array}$ & Yes \\
\hline \multicolumn{7}{|c|}{ Graft function/mortality } \\
\hline Park et al. [22] & $\begin{array}{l}\text { Retrospective } \\
\text { observational cohort } \\
\text { study }\end{array}$ & 2,318 & $\begin{array}{l}\text { Median follow-up } \\
62-64 \text { months }\end{array}$ & na & DCGF and mortality & Yes \\
\hline Djamali et al. [23] & $\begin{array}{l}\text { Retrospective } \\
\text { observational cohort } \\
\text { study }\end{array}$ & 2,128 & $\begin{array}{l}\text { Median follow-up } \\
4.0 \text { years }\end{array}$ & na & $\begin{array}{l}\text { CVEs and all-cause } \\
\text { mortality }\end{array}$ & Yes \\
\hline Brazier et al. [24] & $\begin{array}{l}\text { Retrospective } \\
\text { observational cohort } \\
\text { study }\end{array}$ & 914 & $\begin{array}{l}\text { Median follow-up } \\
47 \text { months }\end{array}$ & na & $\begin{array}{l}\text { Serological biomarkers, } \\
\text { graft failure, death, and } \\
\text { composite outcome }\end{array}$ & Yes \\
\hline Wiegand et al. [25] & Post hoc analysis & 90 & 1 year & na & $\begin{array}{l}\text { Correlation of } \\
\text { bicarbonate and eGFR }\end{array}$ & Yes \\
\hline Schulte et al. [26] & $\begin{array}{l}\text { Retrospective } \\
\text { observational cohort } \\
\text { study }\end{array}$ & 4,741 & $\begin{array}{l}\text { Median follow-up not } \\
\text { reported; endpoints } \\
\text { reported at } 5 \text { years } \\
\text { after KTx }\end{array}$ & na & $\begin{array}{l}\text { DCGF, mortality, and } \\
\text { bone fractures }\end{array}$ & None \\
\hline
\end{tabular}

na, not applicable; BMD, bone mineral density; MA, metabolic acidosis; CVEs, cardiovascular events; DCGF, death-censored graft failure; KTx, kidney transplantation; eGFR, estimated glomerular filtration rate; RCT, randomized controlled trial. * Number of study patients.

\section{Bone Metabolism}

Bone metabolism was the first condition that was investigated in KTRs with MA. An early study identified an association of MA (bicarbonate $<21 \mathrm{mmol} / \mathrm{L}$ ) with low bone mineral density (BMD) measured by dual-energy X-ray absorptiometry (DXA) [62]. An association of MA (bicarbonate $<24 \mathrm{mmol} / \mathrm{L}$ ) with serological biomarkers, such as calcium, phosphorus, 
and intact parathyroid hormone, was identified in another cross-sectional analysis [48]. Recently, patients with MA (bicarbonate $<22 \mathrm{mmol} / \mathrm{L}$ ) from a large French cohort were analyzed according to arterial $\mathrm{pH}$. In this study, acidemia was shown to be associated with altered mineral metabolism, including blood ionized calcium, phosphate, and FGF-23 [24]. However, by now, only one RCT has been performed in KTRs with MA looking at different aspects of bone quality - in particular bone histology [63]. Despite a small sample size, the study protocol was very elaborate, comprising bone biopsies and DXA besides measurements of multiple serological biomarkers. Thirty patients with serum bicarbonate $<24 \mathrm{mmol} / \mathrm{L}$ were treated with either potassium citrate or potassium chloride for 1 year. After 1 year, the bone structure was better preserved in the group treated with potassium citrate than in the group with potassium chloride. According to bone tetracycline labeling and serological markers, more bone turnover was seen in the group with alkali treatment. However, no relevant changes in bone mineral density were detected. In another cross-sectional study, no significant differences were seen in DXA measurements between 36 KTRs with and a control group without RTA [58]. Interestingly, a prospective observational cohort study in a pediatric transplant population identified the degree of MA as a significant predictor of growth [64]. Another cohort study using German health insurance data and ICD (International Statistical Classification of Diseases and Related Health Problems) codes, which is discussed in detail below, did not find any significant differences in the incidence of bone fractures between KTRs without MA, with MA, and with bicarbonate treatment [26].

\section{Cardiovascular Events}

Coronary artery disease, congestive heart failure, and arrhythmia are common among KTRs and account for mortality in many patients. Since MA is associated with several risk factors for cardiovascular disease, a recent large retrospective observational cohort study investigated the association of MA at 1 year post transplantation with cardiovascular events (CVEs) - ischemia, arrhythmia, and heart failure - and all-cause mortality [23]. A tCO $\mathrm{CO}_{2}$ level $<20 \mathrm{mEq} / \mathrm{L}$ was associated with an increased risk for CVEs compared to reference patients with a $\mathrm{tCO}_{2}$ level of $24.0-25.9 \mathrm{mEq} / \mathrm{L}$ with an adjusted hazard ratio of 2.0 (95\% CI 1.29-3.10). Interestingly, this association was mainly driven by ischemic events. The investigators also identified an independent association of MA with all-cause mortality - adjusted hazard ratio 1.43 (95\% CI 1.02-2.02) in the case of $\mathrm{tCO}_{2}$ level $<20 \mathrm{mEq} / \mathrm{L}$ compared to the reference group. Further evidence from RCTs with safety assessment is required to clarify the potential role of alkali treatment in this context. In addition, the impact of sodium load on CVEs should also be investigated when sodium is given as a cation included in the alkali formulation.

\section{Graft Outcome and Mortality}

Although several randomized studies in patients with CKD have demonstrated a positive effect of alkali therapy on CKD progression and mortality, these data are lacking in KTx. To date, only observational studies have been published investigating the association of MA with graft function and/or mortality. A large multicenter retrospective cohort study from South Korea was the first to examine the influence of MA on graft and patient survival involving 2,318 adult KTRs with an average follow-up of 5 years [22]. The authors demonstrated that a tCO ${ }_{2}$ level $<22 \mathrm{mmol} / \mathrm{L}$ at 3 months after KTx was associated with an increased risk of graft loss and death-censored graft failure. In a second model using $\mathrm{tCO}_{2}$ as a time-varying variable and adjusting for several confounding factors, the relationship between MA and graft outcome was even stronger. In addition, MA was associated with a significantly higher risk of mortality, confirming this finding of the study discussed above [23]. Of note, this result was independent of graft function. The lowest risks for graft outcome and mortality were shown for $\mathrm{tCO}_{2}$ levels of 24-28 mmol/L. These findings raise the question whether the arbitrary threshold of 22 
$\mathrm{mmol} / \mathrm{L}$ to define MA is appropriate in KTRs. However, the study population included a high percentage of living kidney donations (approximately 75\%), and the low prevalence of MA in this relatively healthy transplant cohort may limit its generalizability. A French retrospective cohort study including 914 KTRs reported a negative association of arterial bicarbonate levels with allograft loss and death, while baseline $\mathrm{pH}$ levels showed no association [24]. The authors identified 20 and $19 \mathrm{mmol} / \mathrm{L}$ as optimal arterial blood bicarbonate threshold for prediction of allograft loss or death, respectively. Results from a post hoc analysis of an open label RCT at our center showed a positive correlation of serum bicarbonate with eGFR in the first year after transplantation, supporting the hypothesis of a potential role of MA on graft function [25]. Additionally, a retrospective analysis of $430 \mathrm{KTRs}$ from our cohort with a mean observation time of 5 years demonstrated that higher serum bicarbonate levels were associated with long-term graft and patient survival (unpublished data).

So far, there is only one retrospective cohort study on the influence of bicarbonate therapy on death-censored graft failure, bone fractures, and mortality [26]. A total of 4,741 KTRs were allocated to three groups - no acidosis, acidosis, or alkali therapy - according to health insurance codes during the first year after transplantation and were followed up thereafter. The authors found no association of MA with increased frequency of graft failure, death, or bone fractures. In contrast, they saw an increased incidence of graft failure in the group treated with sodium bicarbonate. However, the study has strong limitations, and the results must be interpreted very carefully. The main limitation is certainly the lack of granularity of the encoded health insurance data. Moreover, relevant parameters such as graft function and severity of MA were unknown to the researchers, which may lead to confounding. It is possible that patients with worse graft function and higher risk of graft failure were more likely to receive treatment. These conflicting results underline the unmet need for more evidence. Thus, the results of an ongoing multicenter, single-blinded RCT investigating the effect of sodium bicarbonate on graft function in KTRs with MA over 2 years will be crucial to move an important and evidence-based step forward on this issue [65].

\section{Conclusion}

MA seems to be more common in the kidney transplant population than in CKD patients. Besides mechanisms that have been described in CKD, additional transplant-specific factors play a role in the development of MA. There is increasing evidence that MA may have negative effects on different organ systems in KTRs, including graft function. However, results from the existing, mainly observational studies are conflicting. Since the underlying mechanisms of MA in renal transplant patients are only partially corresponding to CKD patients, specific studies in the transplant population are crucial to identify patients at increased risk for severe complications, such as allograft loss and death. In addition, RCTs on clinical outcomes including safety are still missing and strongly required for guidance of alkali therapy. Implementing alkali treatment into the drug regimen of KTx patients with MA could be a safe and cost-effective therapy and may have the potential to preserve long-term graft function and patient survival.

\section{Conflict of Interest Statement}

The authors have no conflict of interest to declare. 


\section{Funding Sources}

The Preserve-Transplant Study is a multicenter IICT funded by the Swiss National Science Foundation.

\section{Author Contributions}

Both authors contributed important intellectual content during manuscript drafting and accept accountability for the overall work.

\section{References}

1 Kidney Disease: Improving Global Outcomes (KDIGO) CKD Work Group. KDIGO clinical practice guideline for the evaluation and management of chronic kidney disease. Kidney Int Suppl. 2013;3:73-90.

2 Eustace JA, Astor B, Muntner PM, Ikizler TA, Coresh J. Prevalence of acidosis and inflammation and their association with low serum albumin in chronic kidney disease. Kidney Int. 2004;65(3):1031-40.

3 Inker LA, Grams ME, Levey AS, Coresh J, Cirillo M, Collins JF, et al. Relationship of estimated GFR and albuminuria to concurrent laboratory abnormalities: an individual participant data meta-analysis in a global consortium. Am J Kidney Dis. 2019;73(2):206-17.

4 Messa PG, Alfieri C, Vettoretti S. Metabolic acidosis in renal transplantation: neglected but of potential clinical relevance. Nephrol Dial Transplant. 2016;31(5):730-6.

5 Kraut JA, Madias NE. Metabolic acidosis of CKD: an update. Am J Kidney Dis. 2016;67(2):307-17.

6 Kraut JA, Madias NE. Adverse effects of the metabolic acidosis of chronic kidney disease. Adv Chronic Kidney Dis. 2017;24(5):289-97.

7 Kopple JD, Kalantar-Zadeh K, Mehrotra R. Risks of chronic metabolic acidosis in patients with chronic kidney disease. Kidney Int Suppl. 2005;(95):S21-7.

8 Kovesdy CP, Anderson JE, Kalantar-Zadeh K. Association of serum bicarbonate levels with mortality in patients with non-dialysis-dependent CKD. Nephrol Dial Transplant. 2009;24(4):1232-7.

9 Driver TH, Shlipak MG, Katz R, Goldenstein L, Sarnak MJ, Hoofnagle AN, et al. Low serum bicarbonate and kidney function decline: the multi-ethnic study of atherosclerosis (MESA). Am J Kidney Dis. 2014;64(4):53441.

10 Goldenstein L, Driver TH, Fried LF, Rifkin DE, Patel KV, Yenchek RH, et al. Serum bicarbonate concentrations and kidney disease progression in community-living elders: the health, aging, and body composition (Health ABC) study. Am J Kidney Dis. 2014;64(4):542-9.

11 Dobre M, Rahman M, Hostetter TH. Current status of bicarbonate in CKD. J Am Soc Nephrol. 2015;26(3):51523.

12 Menon V, Tighiouart H, Vaughn NS, Beck GJ, Kusek JW, Collins AJ, et al. Serum bicarbonate and long-term outcomes in CKD. Am J Kidney Dis. 2010;56(5):907-14.

13 Scialla JJ, Appel LJ, Astor BC, Miller ER 3rd, Beddhu S, Woodward M, et al. Net endogenous acid production is associated with a faster decline in GFR in African Americans. Kidney Int. 2012;82(1):106-12.

14 Shah SN, Abramowitz M, Hostetter TH, Melamed ML. Serum bicarbonate levels and the progression of kidney disease: a cohort study. Am J Kidney Dis. 2009;54(2):270-7.

15 de Brito-Ashurst I, Varagunam M, Raftery MJ, Yaqoob MM. Bicarbonate supplementation slows progression of CKD and improves nutritional status. J Am Soc Nephrol. 2009;20(9):2075-84.

16 Mahajan A, Simoni J, Sheather SJ, Broglio KR, Rajab MH, Wesson DE. Daily oral sodium bicarbonate preserves glomerular filtration rate by slowing its decline in early hypertensive nephropathy. Kidney Int. 2010;78(3): 303-9.

17 Phisitkul S, Khanna A, Simoni J, Broglio K, Sheather S, Rajab MH, et al. Amelioration of metabolic acidosis in patients with low GFR reduced kidney endothelin production and kidney injury, and better preserved GFR. Kidney Int. 2010;77(7):617-23.

18 Di Iorio BR, Bellasi A, Raphael KL, Santoro D, Aucella F, Garofano L, et al. Treatment of metabolic acidosis with sodium bicarbonate delays progression of chronic kidney disease: the UBI Study. J Nephrol. 2019;32(6):9891001.

19 Goraya N, Simoni J, Jo CH, Wesson DE. Treatment of metabolic acidosis in patients with stage 3 chronic kidney disease with fruits and vegetables or oral bicarbonate reduces urine angiotensinogen and preserves glomerular filtration rate. Kidney Int. 2014;86(5):1031-8.

20 Dubey AK, Sahoo J, Vairappan B, Haridasan S, Parameswaran S, Priyamvada PS. Correction of metabolic acidosis improves muscle mass and renal function in chronic kidney disease stages 3 and 4: a randomized controlled trial. Nephrol Dial Transplant. 2020;35(1):121-9. 
21 Navaneethan SD, Shao J, Buysse J, Bushinsky DA. Effects of treatment of metabolic acidosis in CKD: a systematic review and meta-analysis. Clin J Am Soc Nephrol. 2019;14(7):1011-20.

22 Park S, Kang E, Park S, Kim YC, Han SS, Ha J, et al. Metabolic acidosis and long-term clinical outcomes in kidney transplant recipients. J Am Soc Nephrol. 2017;28(6):1886-97.

23 Djamali A, Singh T, Melamed ML, Stein JH, Aziz F, Parajuli S, et al. Metabolic acidosis 1 year following kidney transplantation and subsequent cardiovascular events and mortality: an observational cohort study. Am J Kidney Dis. 2019;73(4):476-85.

24 Brazier F, Jouffroy J, Martinez F, Nguyen-Khoa T, Anglicheau D, Legendre C, et al. Association of blood bicarbonate and $\mathrm{pH}$ with mineral metabolism disturbance and outcome after kidney transplantation. Am J Transplant. 2020;20(4):1063-75.

25 Wiegand A, Graf N, Bonani M, Frey D, Wüthrich RP, Mohebbi N. Relationship of serum bicarbonate levels with 1-year graft function in kidney transplant recipients in Switzerland. Kidney Blood Press Res. 2019;44(5): 1179-88.

26 Schulte K, Püchel J, Schüssel K, Borzikowsky C, Kunzendorf U, Feldkamp T. Effect of sodium bicarbonate in kidney transplant recipients with chronic metabolic acidosis. Transplant Direct. 2019;5(7):e464.

27 Massry SG, Preuss HG, Maher JF, Schreiner GE. Renal tubular acidosis after cadaver kidney homotransplantation. Studies on mechanism. Am J Med. 1967;42(2):284-92.

28 Wagner CA, Imenez Silva PH, Bourgeois S. Molecular pathophysiology of acid-base disorders. Semin Nephrol. 2019;39(4):340-52.

29 Lotspeich WD. Renal hypertrophy in metabolic acidosis and its relation to ammonia excretion. Am J Physiol. 1965;208:1135-42.

30 Nath KA, Hostetter MK, Hostetter TH. Increased ammoniagenesis as a determinant of progressive renal injury. Am J Kidney Dis. 1991;17(6):654-7.

31 Halperin ML, Ethier JH, Kamel KS. Ammonium excretion in chronic metabolic acidosis: benefits and risks. Am J Kidney Dis. 1989;14(4):267-71.

32 Nagami GT, Hamm LL. Regulation of acid-base balance in chronic kidney disease. Adv Chronic Kidney Dis. 2017;24(5):274-9.

33 Scialla JJ, Anderson CA. Dietary acid load: a novel nutritional target in chronic kidney disease? Adv Chronic Kidney Dis. 2013;20(2):141-9.

34 Burki R, Mohebbi N, Bettoni C, Wang X, Serra AL, Wagner CA. Impaired expression of key molecules of ammoniagenesis underlies renal acidosis in a rat model of chronic kidney disease. Nephrol Dial Transplant. 2015; 30(5):770-81.

35 Vallet M, Metzger M, Haymann JP, Flamant M, Gauci C, Thervet E, et al. Urinary ammonia and long-term outcomes in chronic kidney disease. Kidney Int. 2015;88(1):137-45.

36 Nath KA, Hostetter MK, Hostetter TH. Pathophysiology of chronic tubulo-interstitial disease in rats. Interactions of dietary acid load, ammonia, and complement component C3. J Clin Invest. 1985;76(2):667-75.

37 Wesson DE, Nathan T, Rose T, Simoni J, Tran RM. Dietary protein induces endothelin-mediated kidney injury through enhanced intrinsic acid production. Kidney Int. 2007;71(3):210-7.

38 Wesson DE, Jo CH, Simoni J. Angiotensin II-mediated GFR decline in subtotal nephrectomy is due to acid retention associated with reduced GFR. Nephrol Dial Transplant. 2015;30(5):762-70.

39 Goraya N, Simoni J, Jo C, Wesson DE. Dietary acid reduction with fruits and vegetables or bicarbonate attenuates kidney injury in patients with a moderately reduced glomerular filtration rate due to hypertensive nephropathy. Kidney Int. 2012;81(1):86-93.

40 Raj S, Scott DR, Nguyen T, Sachs G, Kraut JA. Acid stress increases gene expression of proinflammatory cytokines in Madin-Darby canine kidney cells. Am J Physiol Renal Physiol. 2013;304(1):F41-8.

41 Schwarz C, Benesch T, Kodras K, Oberbauer R, Haas M. Complete renal tubular acidosis late after kidney transplantation. Nephrol Dial Transplant. 2006;21(9):2615-20.

42 Better OS. Tubular dysfunction following kidney transplantation. Nephron. 1980;25(5):209-13.

43 Bank N, Aynediian HS. A micropuncture study of the effect of parathyroid hormone on renal bicarbonate reabsorption. J Clin Invest. 1976;58(2):336-44.

44 Ladefoged J. Tubular reabsorption of bicarbonate in transplanted cadaver kidneys. Nephron. 1973;10(4): 216-21.

45 Better OS, Chaimowitz C, Alroy GG, Sisman I. Spontaneous remission of the defect in urinary acidification after cadaver kidney homotransplantation. Lancet. 1970;1(7638):110-2.

46 Wilson DR, Siddiqui AA. Renal tubular acidosis after kidney transplantation. Natural history and significance. Ann Intern Med. 1973;79(3):352-61.

47 Heering P, Ivens K, Aker S, Grabensee B. Distal tubular acidosis induced by FK506. Clin Transplant. 1998; 12(5):465-71.

48 Yakupoglu HY, Corsenca A, Wahl P, Wüthrich RP, Ambühl PM. Posttransplant acidosis and associated disorders of mineral metabolism in patients with a renal graft. Transplantation. 2007;84(9):1151-7.

49 Kocyigit I, Unal A, Kavuncuoglu F, Sipahioglu MH, Tokgoz B, Oymak O, et al. Renal tubular acidosis in renal transplantation recipients. Ren Fail. 2010;32(6):687-90.

50 Stahl RA, Kanz L, Maier B, Schollmeyer P. Hyperchloremic metabolic acidosis with high serum potassium in renal transplant recipients: a cyclosporine a associated side effect. Clin Nephrol. 1986;25(5):245-8. 
51 Watanabe S, Tsuruoka S, Vijayakumar S, Fischer G, Zhang Y, Fujimura A, et al. Cyclosporin a produces distal renal tubular acidosis by blocking peptidyl prolyl cis-trans isomerase activity of cyclophilin. Am J Physiol Renal Physiol. 2005;288(1):F40-7.

52 Mohebbi N, Mihailova M, Wagner CA. The calcineurin inhibitor FK506 (tacrolimus) is associated with transient metabolic acidosis and altered expression of renal acid-base transport proteins. Am J Physiol Renal Physiol. 2009;297(2):F499-509.

53 Devuyst O, Lemaire M, Mohebbi N, Wagner CA. Autoantibodies against intercalated cells in Sjögren's syndrome. Kidney Int. 2009;76(2):229.

54 Mookerjee B, Gault MH, Dossetor JB. Hyperchloremic acidosis in early diagnosis of renal allograft rejection. Ann Intern Med. 1969;71(1):47-58.

55 Batlle DC, Mozes MF, Manaligod J, Arruda JA, Kurtzman NA. The pathogenesis of hyperchloremic metabolic acidosis associated with kidney transplantation. Am J Med. 1981;70(4):786-96.

56 Cho BS, Kim HS, Jung JY, Choi BS, Kim HW, Choi YJ, et al. Severe renal tubular acidosis in a renal transplant recipient with repeated acute rejections and chronic allograft nephropathy. Am J Kidney Dis. 2003;41(2):E6.

57 Probst P, Soleiman A, Zbornay V, Benesch T, Haas M. The effect of kidney transplantation on distal tubular vacuolar H+-ATPase. Transplantation. 2008;85(3):391-7.

58 Keven K, Ozturk R, Sengul S, Kutlay S, Ergun I, Erturk S, et al. Renal tubular acidosis after kidney transplantation--incidence, risk factors and clinical implications. Nephrol Dial Transplant. 2007;22(3):906-10.

59 Dagan A, Eisenstein B, Bar-Nathan N, Cleper R, Krause I, Smolkin V, et al. Tubular and glomerular function in children after renal transplantation. Pediatr Transplant. 2005;9(4):440-4.

60 van den Berg E, Engberink MF, Brink EJ, van Baak MA, Joosten MM, Gans RO, et al. Dietary acid load and metabolic acidosis in renal transplant recipients. Clin J Am Soc Nephrol. 2012;7(11):1811-8.

61 Chan JC, Ma RS, Malekzadeh MH, Hurley JK, Chaimovitz C. Renal response to acute ammonium chloride acidosis in subjects with single kidney. J Urol. 1974;111(3):315-20.

62 Heaf J, Tvedegaard E, Kanstrup IL, Fogh-Andersen N. Bone loss after renal transplantation: role of hyperparathyroidism, acidosis, cyclosporine and systemic disease. Clin Transplant. 2000;14(5):457-63.

63 Starke A, Corsenca A, Kohler T, Knubben J, Kraenzlin M, Uebelhart D, et al. Correction of metabolic acidosis with potassium citrate in renal transplant patients and its effect on bone quality. Clin J Am Soc Nephrol. 2012; 7(9):1461-72.

64 Franke D, Thomas L, Steffens R, Pavičić L, Gellermann J, Froede K, et al. Patterns of growth after kidney transplantation among children with ESRD. Clin J Am Soc Nephrol. 2015;10(1):127-34.

65 Wiegand A, Ritter A, Graf N, Arampatzis S, Sidler D, Hadaya K, et al. Preservation of kidney function in kidney transplant recipients by alkali therapy (preserve-transplant study): rationale and study protocol. BMC Nephrol. 2018;19(1):177. 